The Romance of the Nitrogen Atom.

Wirf reference to the interesting letter by Dr. Irving in Nature of June $\mathrm{r}_{5}$ on "The Romance of the Nitrogen Atom," I should like to point out that ammonia is not so stable as is sometimes imagined. I have shown recently not only that ammonia decomposes slowly at a temperature of about $700^{\circ} \mathrm{C}$., but that the decomposition is irreversible (Proc. Roy. Soc., June), so that it will proceed until no ammonia remains. The rate of decomposition decreases rapidly with temperature, but it appears probable that even at the ordinary temperature of the air the decomposition must still proceed, although with excessive slowness. A mixture of nitrogen, hydrogen, and ammonia would thus appear to be in "false equilibrium," in the same way as a mixture of hydrogen, oxygen, and water vapour, but in the opposite sense. The "silent discharge" will decompose as well as synthesise ammonia, and brings about a state of equilibrium. Sparking has also the same effect. In these cases the equilibrium is a true one, so long as the experimental conditions remain unaltered, and it ensues when the rates of formation and decomposition of the ammonia are equal.

University College, Cardiff, June i7.

\section{Notes on the Habits of Testacella.}

UNDER the above heading in NATURE, vol, xxxiv. p. 6I7 (October 28, 1886), Prof. E. B. Poulton recorded the capture of twenty-two specimens of this rare slug upon a wall in Oxford. On that occasion there had been exceptionally heavy rains, and it was suggested that the animals had been driven out of their usual habitat, the earth, as it became sodden with moisture. I am in a position to confirm the accuracy of this suggestion. Last evening I captured five specimens of Testacella haliotidea upon a stone wall near Charterhouse. The slugs were apparently crawling out of the ivy which thickly clothes the top of the wall, and were making their way back to the earth. During the previous eight days no less than 3.80 inches of rain fell at this place. It seems probable that the slugs had taken refuge in the dense shelter of the ivy while the soil was unfit for them, and that on the return of hot, dry weather were once again seeking their subterranean quarters.

Charterhouse, Godalming, June is.

\section{Researches on Ovulation.}

I SHOULD be greatly obliged if you would allow me to state in your Journal that the paragraph on "ovulation" in relation to cestrus on p. $5^{1} 7$ of my text-book on the "Vertebrata,", which was issued in March last, contains references to discoveries which were at that time unpublished, and that by inadvertence I omitted to direct attention to this. The information was supplied to me by Mr. Walter Heape. The facts relating to rabbits were discovered by him, those relating to ferrets and dogs by $\mathrm{Mr}$. F. H. A. Marshall. These observations, with others, have recently been separately communicated to the Royal Society for publication in the Proceedings.

Trinity College, Cambridge, June 16.

A. SEDGWICK.

\section{ABORIGINAL METHODS OF DETERMININC} THE SEASONS.

$\mathrm{A}^{\mathrm{N}}$ important and timely confirmation of the astroA nomical significance attached to the stone circles of Britain, and to the pyramids and temples of Egypt, comes from the Far East. From an interesting paper (Journal of the Asiatic Society, Straits Branch, January) by Dr. Charles Hose, who has made a special study of the subject, we learn that the natives of Borneo are at the present day using just the same general principles in determining the advent of their agricultural seasons as were used by the early Britons and the ancient Egyptians between one and two thousand years B.c. It will be remembered that, in Greece, Mr. Penrose observed (see Nature, April 6) that the Hecatompedon and the older Erechtheum, built about 1495 B.C. and 2020 B.c. respectively, were oriented to the cluster of the Pleiades at its heliacal rising on May morning. In Egypt, Sir Norman Lockyer found that the same asterism, as the deity Nit-Isis, was probably employed as the warning star for sunrise at the vernal equinox ("Dawn of Astronomy," I894, p. 388).

Although in Great Britain there are a great number of stone circles, their astronomical significance has, until quite recently, not been satisfactorily understood. However, the recognition of Stonehenge as a solstitial temple (Proc. Roy. Soc., vol. lxix. pp. 137-147) led to an inquiry into their possible character as observatories, used by priest-astronomers to determine the advent of the seed-time and other festivals, and the investigation met with gratifying results at the outset. In the case of "The Hurlers," a group of three stone circles situated near Liskeard, in Cornwall, prima facie evidence was found that they were arranged in their present positions, and the stones around them placed in accordance, so that the officiating priesthood could announce to the people the arrival of the crucial seasons in the agricultural year. Among the stones used as azimuth marks at "The Hurlers," there is one with an amplitude of E. $\mathrm{I}^{\circ} \mathrm{N}$., which would mark the exact heliacal rising of the Pleiades on May morning about the year I6oo B.c. (Proc. Roy. Soc., March 30). In addition to the Pleiades, it has been found that the belt of Orion was frequently used as the warning sign.

Now we learn from Dr. Hose's researches that, at the present time, the natives of Borneo, more especially the Dyaks, are using the same stars in much the same way to determine the season of the year ordained by the local meteorological conditions as the time for the preparation of the ground on which they hope to grow their food supply for the ensuing twelvemonth. During the semester October to April the prevailing wind in Borneo is from the north-east, and brings rain with it; during the other six months of the year the direction of the prevalent wind is changed, but it brings none of the month-tomonth variations of conditions which-in lieu of more refined knowledge--would lead the agriculturist of the temperate zones to a more or less approximate knowledge of the season.

In Egypt it was the advent of the Nile flood which fixed the seed-time, and for which the celestial heralds were observed; in Britain it 'was, as it is now, the advent of the warm, sunny weather that was the matter of importance; in Borneo it is the commencement of the driest season that has to be recognised, because the land which is to be cultivated is overgrown by jungle or forest, and, before seed may be sown thereon, a clearance must be effected. Like the Malayans, the Dyak might use the moon as his indicator, but then, like the Malayans, he would probably get about eleven days wrong every year, a serious matter where the dry season is of short duration. The variation of the length of the day is too small in the tropics to give a definite cue as to the commencement of any special season. Consequently, the Dyaks and many of the smaller neighbouring tribes have recourse to the stars, and the stars chosen as the heralds are the Pleiades (" bintang banyak") and Orion's belt ("bintang tiga "). The native names are borrowed from the Malays, and this probably indicates that the similar use of these stars is not totally unknown among the latter. The alternative expression used by the Dyaks in naming the Pleiades is "Apai andau," meaning "the father of the day," probably so called because it is the heliacal rising of them that the natives watch for before commencing their clearing process. In Borneo it is, at present, merely an observation of the Pleiades

No. 1860 , VOL. 72$]$ 
themselves that is made; the subsequent sunrise has no urgent interest for them; but in Egypt and Britain the stars were simply the heralds of the greater luminary for which the religious sacrifice had to be prepared by the priests.

The method of making the determination is as follows:-The surrounding terrestrial phenomena suggest the approach of the dry season, and two men are then sent into the jungle-which probably means any open space with a clear horizon-to await the celestial sign. After watching for a few nights, may be a month, the Pleiades are seen on the horizon just before the light of the rising sun overcomes that of the stars. Then the messenger-astronomers return to their village and announce the fact, and the work on the forest is commenced. Should the tribe have been so misled by the workings of terrestrial nature as to delay the making of the observation until Orion's belt rises before daylight, it means that they must work "double-shift" in order to get their ground cleared in time for the vegetable matter to dry thoroughly ere the season for burning it comes round. After this recognition of the season the interest of the tribe in celestial phenomena becomes dormant until the services of the latter are again required. Not until the Pleiades reach the zenith before sunrise do they consider it advisable to set fire to the refuse, for unless the latter has had enough time to dry thoroughly it will not be completely consumed, and the ground will be of no use for ricegrowing.

With the neighbouring tribes, the Kenyahs and the Kayans, the method of determining the seasons is rather more scientific, exhibiting an advanced state of knowledge. These people are acquainted with the various phenomena attending the apparent diurnal and annual movements of the sun. They know that the noon shadow is the shortest, and that it always lies in the same straight line, sometimes to the north, sometimes to the south. Consequently, they utilise this knowledge by measuring either the length of the shadow cast by a gnomon set up vertically on levelled ground, or else the length of a beam of sunlight projected through a small hole in the roof of a hut upon a plank, laid horizontally on the foor by packing it up until round discs will not roll when placed on edge on its surface. The shàdow, or beam of light, is measured by means of a stick, on which there are a series of notches. The distance of each notch from the end of the stick represents the length of shadow which experience, tinged, maybe, with superstition, has taught these people to recognise as favourable, or the reverse, for the prosecution of their various agricultural operations. The stick, known as "asa do," is carefully preserved in the keeping of an older member of the tribe, duly elected to this office on account of his superior wisdom and his incapacity for more strenuous manual labour, and it is he who watches that the beam is not measured obliquely, and announces the advent of the favourable season for sowing operations to commence.

A striking phase of the question, showing how limited is the original knowledge, possibly appears in the selection of the Pleiades and Orion's belt as the "warners." Why should these two groups be selected by so many different tribes in so many widely separated ages? A plausible explanation seems to be that their forms are instantly recognisable. Whilst the aboriginal watcher would probably not be able to recognise the isolated, though bright, stars of the large constellations, especially if, as is the case with the Dyaks, no azimuth marks were employed, he could not possibly confuse either of these with any other group of stars.

No. I860, VOL. 72]
THE FOURTH INTERNATIONAL ORNITHOLOGICAL CONGRESS. $T_{\text {assembled in London on Monday, June }}^{\mathrm{HE}} \mathbf{I 2}$ under the presidency of Dr. R. Bowdler Sharpe, and continued in session to the end of the week. The congress was instituted at Vienna in 1887 under the patronage of the Crown Prince Rudolph of Austria. The second congress was held at Buda-Pesth, and the third at Paris in I9oI, so that the London congress was the fourth of the series. It was well attended by both British and foreign ornithologists-to the number of rather more than 300 . They commenced their work on June 12 by an informal meeting at the Imperial Institute, South Kensington, which was the headquarters of the congress during its session.

The British ornithologists were well represented by Dr. Hartert, of Tring, and Mr. Bonhote, of Cambridge, who acted most efficiently as secretaries, while Mr. C. E. Fagan, of the British Museum, looked after the finances as treasurer. These gentlemen were assisted in their duties by Dr. Godman, Mr. Meade-Waldo, Mr. Ogilvie-Grant, Dr. Penrose, the Hon. Walter Rothschild, Dr. Sclater, and Mr. Witherby, who were all members of the organising committee. Many other well known British ornithologists attended the meetings, such as Sir Walter Buller, Dr. Butler, Mr. Dresser, Colonel GadwinAusten, Mr. Harting, Mr. Pearson, Mr. Pycraft, Mr. Howard Saunders, and Mr. D. Seth-Smith. The French ornithologists were represented by Dr. Oustalet and Dr. Burcau, the German by Graf Hans v. Berlepsch, Dr. Blasius, and Prof. Reichenow, the Dutch by Dr. Büttikofer and Baron Snouckaert van Schauburg, the Austrian by Dr. Lorenz and Dr. Reiser, and the Italian by Dr. Giglioli and Count Arrigoni degli Oddi. From America came Mr. F. M. Chapman and Dr. Stejneger, from Switzerland Prof. Fatio and Dr. Studer, from Russia Dr. Bianchi and Baron Loudon, from Bulgaria Dr. Paul Leverkühn, from Canada Mr. Fleming, from Hungary Dr. Herman, and from Belgium Dr. A. Dubois, all names well known in ornithological science.

The first general meeting of the congress took place in the morning of June 13 , when Dr. Oustalet, the last president, gave up the chair to Dr. Bowdler Sharpe, the new president, who delivered a most instructive address on the origin and progress of the great national bird-collection in the British Museum, which is under his charge. The meeting was then divided into five sections:--(I) systematic ornithology and distribution; (2) migration; (3) biology and oology; (4) economic ornithology; and (5) aviculture, which sat at stated periods throughout the week. To the first section, which was presided over by Dr. P. L. Sclater, F.R.S., about fourteen communications were made, among which were papers by Graf v. Berlepsch on new neotropical birds, by Mr. Pycraft on the importance of the study of nestling birds, which was illustrated by various pregnant instances of the secrets they have already revealed and are likely to betray in the future, and by Padre Schmitz on the birds of Madeira. In this section also, Dr. Reiser, of Serajevo, exhibited the series of NorthBrazilian birds which had been obtained during Dr. Steindachner's recent expedition to the Rio St. Francisco, and Mr. Walter Rothschild showed his unique copy of "Les Voyages de Sieur B.," with the map attached, which contains much information on the now extinct birds of the Mascarene Island's.

In the second section, which met on Tuesday and Saturday, with Dr. Herman, of Buda-Pesth, in the chair, Mr. J. H. Fleming gave particulars of an unusual migratory visit of Brunnich's murre to the 